\title{
Difference in size between spermatozoa from the cauda epididymidis and the caput epididymidis of the rat
}

\author{
Janet Brotherton
}

Department of Gynaecological Endocrinology, Sterility and Family Planning, Klinikum Steglitz of the Free University of Berlin, Hindenburgdamm, 30, 1000 Berlin 45, Germany

The Coulter Counter has been used to determine the number and equivalent spherical volume of ejaculated or epididymal spermatozoa from several species, including man (Brotherton \& Barnard, 1974; Brotherton, 1975a,b). In the present study, spermatozoa were obtained from the cauda and caput epididymidis of individual Sprague-Dawley rats, weighing 300-350 g, and their size determined and compared.

The spermatozoa were extruded from the lacerated coils of the cauda and caput epididymidis (see Glover \& Nicander, 1971) of each rat into a suitable volume of Isoton reagent (Coulter Electronics Ltd) to give a dilution of about $6-14 \times 10^{4}$ spermatozoa/ml. Counting and sizing was carried out as described previously using a Coulter Counter, Model $Z_{B}$ Industrial, with an aperture of nominal diameter $70.7 \mu \mathrm{m}$. The nominal machine constant for this aperture, $K_{N}=22.625$, was used throughout and hence, taken in conjunction with the machine settings of $I=\frac{1}{4}, A=\frac{1}{2}, \mathbf{M}=2$ and $\mathbf{G}=\mathbf{O}$, the machine value, $\mathrm{F}$, was $1.414 \mu \mathrm{m}^{3}$ per unit of threshold.

Table 1. Differences in size between spermatozoa from the cauda and caput epididymidis of the rat

\begin{tabular}{|c|c|c|c|c|c|c|c|}
\hline & \multicolumn{5}{|c|}{ Animal number } & \multirow[b]{2}{*}{ Mean } & \multirow[b]{2}{*}{ \pm S.D. } \\
\hline & 1 & 2 & 3 & 4 & 5 & & \\
\hline \multicolumn{8}{|l|}{ Caput epididymidis } \\
\hline \multicolumn{8}{|l|}{ Threshold (T) } \\
\hline Minimum & $28 \cdot 5$ & $26 \cdot 5$ & $29 \cdot 0$ & $25 \cdot 0$ & $28 \cdot 0$ & & \\
\hline Approx. mode & $49 \cdot 0$ & $55 \cdot 5$ & $45 \cdot 0$ & $45 \cdot 0$ & $42 \cdot 0$ & & \\
\hline Mean $\left(T_{\frac{1}{2}}\right)$ & $53 \cdot 0$ & $58 \cdot 0$ & $55 \cdot 5$ & $52 \cdot 5$ & $56 \cdot 5$ & & \\
\hline \multicolumn{8}{|l|}{ Volume $\left(\mu \mathrm{m}^{3}\right)$} \\
\hline Minimum & $40 \cdot 30$ & $37 \cdot 47$ & $41 \cdot 01$ & $35 \cdot 35$ & $39 \cdot 59$ & $38 \cdot 74$ & $2 \cdot 07$ \\
\hline Mode & $69 \cdot 29$ & 78.48 & 63.63 & 63.63 & $59 \cdot 39$ & $66 \cdot 88$ & $6 \cdot 60$ \\
\hline Mean & $74 \cdot 94$ & $82 \cdot 01$ & 78.48 & $74 \cdot 24$ & $79 \cdot 89$ & $77 \cdot 91$ & $2 \cdot 95$ \\
\hline \multicolumn{8}{|l|}{ Total spermatozoa } \\
\hline$\left(\times 10^{6} /\right.$ animal $)$ & $161 \cdot 7$ & $139 \cdot 0$ & $165 \cdot 5$ & $239 \cdot 6$ & $179 \cdot 1$ & $177 \cdot 0$ & \\
\hline \multicolumn{8}{|l|}{ Cauda epididymidis } \\
\hline \multicolumn{8}{|l|}{ Threshold (T) } \\
\hline Minimum & $33 \cdot 0$ & $33 \cdot 0$ & $35 \cdot 5$ & 32.0 & $28 \cdot 0$ & & \\
\hline Approx. mode & $53 \cdot 5$ & $52 \cdot 2$ & $54 \cdot 5$ & $53 \cdot 0$ & $52 \cdot 0$ & & \\
\hline \multirow{2}{*}{\multicolumn{8}{|c|}{ Volume $\left(\mu \mathrm{m}^{3}\right)$}} \\
\hline & & & & & & & \\
\hline Minimum & $46 \cdot 66$ & 46.66 & $50 \cdot 20$ & $45 \cdot 25$ & $39 \cdot 59$ & $45 \cdot 76$ & $3 \cdot 45^{*}$ \\
\hline Mode & $75 \cdot 65$ & $74 \cdot 24$ & $77 \cdot 06$ & 74.94 & $73 \cdot 53$ & $75 \cdot 08$ & $1 \cdot 22 * *$ \\
\hline Mean & $84 \cdot 13$ & $89 \cdot 08$ & $90 \cdot 50$ & 83.43 & $85 \cdot 55$ & $86 \cdot 54$ & $2 \cdot 78 * * *$ \\
\hline \multicolumn{8}{|l|}{ Total spermatozoa } \\
\hline$\left(\times 10^{6}\right.$ /animal $)$ & $63 \cdot 8$ & $24 \cdot 2$ & $60-0$ & $92 \cdot 7$ & $75 \cdot 0$ & $63 \cdot 1$ & \\
\hline \multicolumn{8}{|l|}{ Loss in mean volume } \\
\hline$\mu \mathrm{m}^{3}$ & $9 \cdot 19$ & 7.07 & $12 \cdot 02$ & $9 \cdot 19$ & 5.66 & 8.63 & $2 \cdot 16$ \\
\hline$\%$ & $10 \cdot 9$ & $7 \cdot 9$ & $13 \cdot 3$ & $11 \cdot 0$ & $6 \cdot 6$ & $10 \cdot 0$ & $2 \cdot 4$ \\
\hline
\end{tabular}

Significantly different $* P<0.01 ; * * P<0.05 ; * * * P<0.005$ 
The agreement between the size distribution curves for the spermatozoa from the caput or cauda epididymidis from the epididymides of individual rats was very close. The sperm volumes at the minimum, approximate mode (of a broad peak) and mean of the size distribution curves were significantly less (about $10 \%$ ) for the spermatozoa from the cauda epididymidis than those from the caput (Table 1).

It is known that during their passage through the epididymis spermatozoa undergo changes in structure and function which collectively are said to reflect a process of maturation (Glover,1974). These changes result in the spermatozoa aquiring the ability to fertilize and a capacity for vigorous motility if removed from the epididymis and exposed to oxygen or a glycolisable sugar such as fructose. The structural changes reported (Glover, 1974) for spermatozoa of rabbits, guinea-pigs and bulls during transit through the epididymis suggest that the spermatozoa undergo dehydration. The present findings of a change in total sperm volume are consistent with the occurrence of such dehydration.

\section{References}

Brotherton, J. \& BARNARD, G. (1974) Estimation of the number, mean size and size distribution of human spermatozoa in oligospermia using a Coulter Counter. J. Reprod. Fert. 40, 341-357.

BRotherton, J. (1975a) The counting and sizing of spermatozoa from ten animal species using a Coulter Counter. Andrologia 7, 169-185.

Brotherton, J. (1975b) The interconversion of machine settings and size determinations between seven models of Coulter Counter as illustrated by values for human spermatozoa. Phys. Med. Biol. 20, 816-824.
Glover, T.D. (1974) Recent progress in the study of male reproductive physiology: testis stimulation; sperm formation, transport and maturation (epididymal physiology); semen analysis, storage and artificial insemination. In MTP International Review of Science; Physiology, Series One, Vol. 8, Reproductive Physiology, pp. 221-276. Ed. R.O. Greep. Butterworths, London.

Glover, T.D. \& NiCANDER, L. (1971) Some aspects of structure and function in the mammalian epididymis. J. Reprod. Fert., Suppl. 13, 39-50.

Received 11 March 1976 